\title{
Ensaio \\ 8 DE MARÇO: CONQUISTAS E CONTROVÉRSIAS
}

\author{
EVA ALTERMAN BLAY
}

Resumo: O Dia Internacional da Mulher foi proposto por Clara Zetkin em 1910 no II Congresso Internacional de Mulheres Socialistas. Nos anos posteriores a 1970 este Dia passou a ser associado a um incêndio que ocorreu em Nova lorque em 1911. Neste artigo procuro recuperar a história do Dia 8 de Março e as distorções que têm sido feitas sobre ele e sobre a luta feminista.

Palavras-chave: história do feminismo, operárias judias, operárias italianas, política, movimentos sociais.

O dia 8 de março é dedicado à comemoração do Dia Internacional da Mulher. Atualmente tornou-se uma data um tanto festiva, com flores e bombons para uns. Para outros é relembrada sua origem marcada por fortes movimentos de reivindicação política, trabalhista, greves, passeatas e muita perseguição policial. É uma data que simboliza a busca de igualdade social entre homens e mulheres, em que as diferenças biológicas sejam respeitadas mas não sirvam de pretexto para subordinar e inferiorizar a mulher.

\section{As mulheres faziam parte das "classes perigosas"}

No século XIX e no início do XX, nos países que se industrializavam, o trabalho fabril era realizado por homens, mulheres e crianças, em jornadas de 12, 14 horas, em semanas de seis dias inteiros e freqüentemente incluindo as manhãs de domingo. Os salários eram de fome, havia terríveis condições nos locais da produção e os proprietários tratavam as reivindicações dos trabalhadores como uma afronta, operárias e operários considerados como as "classes perigosas".' Sucediam-se as manifestações de trabalhadores, por melhores salários, pela redução das jornadas e pela proibição do trabalho infantil. A cada conquista, o movimento operário iniciava outra fase de reivindicações, mas em nenhum momento, até por volta de 1960, a luta sindical teve o objetivo de que homens e mulheres recebessem salários iguais, pelas mesmas tarefas. ${ }^{2}$ As trabalhadoras participavam das lutas gerais mas, quando se tratava de igualdade salarial, não eram consideradas. Alegava-se que as demandas das mulheres afetariam a "luta geral", prejudicariam o salário dos homens e, afinal as mulheres apenas "completavam" o salário masculino.

1 CHEVALIER, 1984.

${ }^{2}$ CHOMBART DE LAWE, M. J.; CHOMBART DE LAWE, Paul Henri et al.. 1963. 
Subjacente aos grandes movimentos sindicais e políticos emergiam outros, construtores de uma nova consciência do papel da mulher como trabalhadora e cidadá. Clara Zetkin, Alexandra Kollontai, Clara Lemlich, Emma Goldman, ${ }^{3}$ Simone Weil ${ }^{4}$ e outras militantes dedicaram suas vidas ao que posteriormente se tornou o movimento feminista.

\section{Clara Zetkin propôs o Dia Internacional da Mulher}

Clara Zetkin (1857-1933), alemã, membro do Partido Comunista Alemão, deputada em 1920, militava junto ao movimento operário e se dedicava à conscientização feminina. Fundou e dirigiu a revista lgualdade, que durou 16 anos (1891-1907).

Líderes do movimento comunista como Clara Zetkin e Alexandra Kollontai ou anarquistas como Emma Goldman lutavam pelos direitos das mulheres trabalhadoras, mas o direito ao voto as dividia: Emma Goldman ${ }^{5}$ afirmava que o direito ao voto não alteraria a condição feminina se a mulher não modificasse sua própria consciência.

Ao participar do II Congresso Internacional de Mulheres Socialistas, em Copenhagem, em 1910, Clara Zetkin propôs a criação de um Dia Internacional da Mulher sem definir uma data precisa. ${ }^{6}$. Contudo, vê-se erroneamente afirmado no Brasil e em alguns países da América Latina que Clara teria proposto o 8 de Março para lembrar operárias mortas num incêndio em Nova lorque em 1857. Os dados a seguir demonstram que os fatos se passaram de maneira diferente.

\section{O movimento operário nos Estados Unidos}

Assim como na Europa, era intenso o movimento trabalhador nos Estados Unidos desde a segunda metade do século XIX, sobretudo nos setores da produção mineira e ferroviária e no de tecelagem e vestuário.

A emergente economia industrial norte-americana, muito instável, era marcada por crises. Nesse contexto, em 1903 formou-se, pela ação de sufragistas e de profissionais liberais, a Women's Trade Union League 7 para organizar trabalhadoras assalariadas. Com as crises industriais de 1907 e 1909 reduziu-se o salário dos trabalhadores, e a oferta de mão-de-obra era imensa, dada a numerosa imigração proveniente da Europa. Grande parte dos operários e operárias era de imigrantes judeus, muitos com um passado de militância política.

No último domingo de fevereiro de 1908, mulheres socialistas dos Estados Unidos fizeram uma manifestação a que chamaram Dia da Mulher, reivindicando o direito ao voto e melhores condições de trabalho. No ano seguinte, em Manhatan, o Dia da Mulher reuniu 2 mil pessoas. ${ }^{8}$

Problemas muito conhecidos do operariado latino-americano impeliam trabalhadores e trabalhadoras a aderir às manifestações públicas por salários e pela redução do horário de trabalho. Embora o setor industrial tivesse algumas grandes empresas, predominavam as pequenas, o que dificultava a agregação e unicidade das reivindicações. O movimento por uma organização sindical era intenso e liderado no setor de confecções e vestuário por trabalhadores judeus com experiência política sindical,

\footnotetext{
${ }^{3} \mathrm{LOBO}, 1983$.

${ }^{4}$ BOSI, 1982.

${ }^{5}$ LOBO, 1983.

${ }^{6} \mathrm{Em}$ alguns países o Dia foi comemorado em 28 de fevereiro ou em 15 de março.

${ }^{7}$ Sobre a Women's Trade Union League, ver também SHEPHERD, 1993, p. 247-258.

${ }^{8}$ ISIS CREATION...
} 
especialmente da União Geral dos Trabalhadores Judeus da Rússia e da Polônia (Der Alguemayner Yiddisher Arbeterbund in Russland un Poyln - BUND) 9

Para desmobilizar $O$ apelo das organizações e controlar a permanência dos trabalhadores/as, muitas fábricas trancavam as portas dos estabelecimentos durante 0 expediente, cobriam os relógios e controlavam a ida aos banheiros. Mas as difíceis condições de vida e os baixíssimos salários eram forte incentivo para a presença de operários e operárias nas manifestações em locais fechados ou na rua.

Uma das fábricas, a Triangle Shirtwaist Company (Companhia de Blusas Triângulo), para se contrapor à organização da categoria, criou um sindicato interno para seus trabalhadores/as. Em outra fábrica, algumas trabalhadoras que reclamavam contra as condições de trabalho e salário foram despedidas e pediram apoio ao United Hebrew Trade, Associação de Trabalhadores Hebreus. Então as trabalhadoras da Triangle quiseram retirar alguns recursos do sindicato interno para ajudar as companheiras mas não 0 conseguiram. Fizeram piquetes na porta da Triangle, que contratou prostitutas para se misturarem às manifestantes, pensando assim dissuadi-las de seus propósitos. Ao contrário, o movimento se fortaleceu.

Uma greve geral começou a ser considerada pelo presidente da Associação dos Trabalhadores Hebreus, Bernardo Weinstein, sempre com o objetivo de melhorar as condições de trabalho da indústria de roupas. A idéia se espalhou e, em 22 de novembro de 1909, organizou-se uma grande reunião na Associação dos Tanoeiros liderada por Benjamin Feigenbaum e pelo Forward. ${ }^{10} \mathrm{~A}$ situação era extremamente tensa e, durante a reunião, subitamente uma adolescente, baixa, magra, se levantou e pediu a palavra: "Estou cansada de ouvir oradores falarem em termos gerais. Estamos aqui para decidir se entramos em greve ou não. Proponho que seja declarada uma greve geral agora!". A platéia apoiou de pé a moção da jovem Clara Lemlich."

\section{Política e etnia}

No movimento dos trabalhadores as relações étnicas tinham peso fundamental, razão pela qual, para garantir um compromisso com a greve, Feigenbaum usou um argumento de extraordinária importância religiosa para os judeus. Ele perguntou à assembléia: "Vocês se comprometerão com o velho mandamento judaico?" Uma centena de mãos se ergueram e todos gritaram: "Se eu esquecer de vós, ó Jerusalém, que eu perca minha mão direita"..$^{2}$ Era um juramento de que não furariam a greve.

Cerca de 15 mil trabalhadores do vestuário, a maioria moças, entraram em greve, provocando o fechamento de mais de 500 fábricas. Jovens operárias italianas aderiram, houve prisões, tentativas de contratar novas trabalhadoras, o que tornou o clima muito tenso. A direção da greve ficou com a Associação dos Trabalhadores Hebreus e com o Sindicato Internacional de Trabalhadores na Confecção de Roupas de Senhoras (International Ladies' Garment Workers' Union - ILGWU). ${ }^{13}$

À medida que as grandes empresas cederam algumas reivindicações, a greve foi se esvaziando e se encerrou em 15 de fevereiro de 1910 depois de 13 semanas.

\footnotetext{
9 MINCZELES, 1995.

${ }^{10}$ Jornal de esquerda escrito parcialmente em ídiche. Forward tem sido traduzido por Avante.

1 SANDERS, 1987, p. 400.

12 SANDERS, 1987, p. 396-400.

${ }^{13}$ Esta greve foi encerrada em 15 de fevereiro de 1910, pois os trabalhadores das grandes empresas conquistaram melhorias.
} 


\section{O incêndio}

Pouco tinha sido alterado, sobretudo nas fábricas de pequeno e médio porte, e os movimentos reivindicatórios retornaram. A reação dos proprietários repetia-se: portas fechadas durante o expediente, relógios cobertos, controle total, baixíssimos salários, longas jornadas de trabalho.

O dia 25 de março de 1911 era um sábado, e às 5 horas da tarde, quando todos trabalhavam, irrompeu um grande incêndio na Triangle Shirtwaist Company, ${ }^{14}$ que se localizava na esquina da Rua Greene com a Washington Place. A Triangle ocupava os três últimos de um prédio de dez andares. O chão e as divisórias eram de madeira, havia grande quantidade de tecidos e retalhos, e a instalação elétrica era precária. Na hora do incêndio, algumas portas da fábrica estavam fechadas. Tudo contribuía para que o fogo se propagasse rapidamente.

A Triangle empregava 600 trabalhadores e trabalhadoras, a maioria mulheres imigrantes judias e italianas, jovens de 13 a 23 anos. Fugindo do fogo, parte das trabalhadoras conseguiu alcançar as escadas e desceu para a rua ou subiu para 0 telhado. Outras desceram pelo elevador. Mas a fumaça e o fogo se expandiram e trabalhadores/as pularam pelas janelas, para a morte. Outras morreram nas próprias máquinas. O Forward publicou terríveis depoimentos de testemunhas e muitas fotos. ${ }^{15}$

Morreram 146 pessoas, 125 mulheres e 21 homens, na maioria judeus.

A comoção foi imensa. No dia 5 de abril houve um grande funeral coletivo que se transformou numa demonstração trabalhadora. Apesar da chuva, cerca de 100 mil pessoas acompanharam o enterro pelas ruas do Lower East Side. No Cooper Union falou Morris Hillquit e no Metropolitan Opera House, o rabino reformista Stephen Wise.

A tragédia teve conseqüências para as condições de segurança no trabalho e sobretudo serviu para fortalecer o ILGWU.

Para autores como Sanders, ${ }^{16}$ todo o processo, desde a greve de 1909, mais o drama do incêndio da Triangle, acabou fortalecendo o reconhecimento dos sindicatos. $O$ ILGWU, de conotação socialista e um dos braços mais 'radicais' do American Federation of Labour (AFL), se tornou o maior e mais forte dos Estados Unidos naquele momento.

Atualmente no local onde se deu o incêndio foi construída a Universidade de Nova lorque. Uma placa, lembrando o terrível episódio, foi lá colocada:

Neste lugar, em 25 de março de 1911, 146 trabalhadores perderam suas vidas no incêndio da Companhia de Blusas Triangle. Deste martírio resultaram novos conceitos de responsabilidade social e legislação do trabalho que ajudaram a tornar as condições de trabalho as melhores do mundo (ILGWU). ${ }^{17}$

\section{Mulheres e movimentos sociais}

No século $X X$, as mulheres trabalhadoras continuaram a se manifestar em várias partes do mundo: Nova lorque, Berlim, Viena (1911); São Petersburgo (1913). Causas e datas variavam. Em 1915, Alexandra Kollontai organizou uma reunião em Cristiana, perto de Oslo, contra a guerra. Nesse mesmo ano, Clara Zetkin faz uma conferência sobre a mulher.

\footnotetext{
14 SANDERS, 1987, p. 394.

${ }^{15}$ HOWE E LIBO, 1979, p. 186.

${ }^{16}$ SANDERS, 1987.

17 SANDERS, 1987, p. 393.
} 
Em 8 de março 1917 (23 de fevereiro no Calendário Juliano), trabalhadoras russas do setor de tecelagem entraram em greve e pediram apoio aos metalúrgicos. Para Trotski esta teria sido uma greve espontânea, não organizada, ${ }^{18}$ e teria sido o primeiro momento da Revolução de Outubro.

Na década de 60, o 8 de Março foi sendo constantemente escolhido como o dia comemorativo da mulher e se consagrou nas décadas seguintes. Certamente esta escolha não ocorreu em conseqüência do incêndio na Triangle, embora este fato tenha se somado à sucessão de enormes problemas das trabalhadoras em seus locais de trabalho, na vida sindical e nas perseguições decorrentes de justas reivindicações.

\section{Lenin: o que importava era a política de massas e não o direito das mulheres}

Mulheres e homens jovens tinham muitas outras preocupações além das questões trabalhistas e do sistema político. Nem sempre a liderança comunista entendia essas necessidades, como foi o caso de Lenin e de muitos outros líderes. Em seu Diário, Clara Zetkin relata o que ouvira do camarada e amigo Lenin, ao visitá-lo no Kremlin, em 1920. ${ }^{19}$ Lenin lamentava o descaso pelo Dia Internacional da Mulher que ela propusera em Copenhagem, pois este teria sido um oportuno momento para se criar um movimento de 'massa', internacionalizar os propósitos da Revolução de 17, agitar mulheres e jovens. Para alcançar este objetivo, afirmava ele, era necessário discutir exc/usivamente os problemas políticos e não perder tempo com aquelas discussões que os jovens trabalhadores traziam para os grupos políticos, como casamento e sexo. ${ }^{20}$ Lenin estendia suas críticas ao trabalho de Rosa Luxemburgo com prostitutas: "Será que Rosa Luxemburgo não encontrava trabalhadores para discutir, era necessário buscar as prostitutas?"21

Esta visão de Lenin fez escola na esquerda. A experiência do 'amor livre' nos primeiros anos pós-Revolução trouxe enormes conflitos que levaram à restauração do sistema de família regulamentado pelo contrato civil. Temas relativos ao corpo, à sexualidade, à reprodução humana, relação afetiva entre homens e mulheres, aborto, só foram retomados 40 anos mais tarde pelo movimento feminista.

\section{O 8 de Março no Brasil}

No Brasil vê-se repetir a cada ano a associação entre o Dia Internacional da Mulher e o incêndio na Triangle, quando na verdade Clara Zetkin o tenha proposto em 1910, um ano antes do incêndio. É muito provável que o sacrifício das trabalhadoras da Triangle tenha se incorporado ao imaginário coletivo da luta das mulheres. Mas o processo de instituição de um Dia Internacional da Mulher já vinha sendo elaborado pelas socialistas americanas e européias há algum tempo e foi ratificado com a proposta de Clara Zetkin.

Nas primeiras décadas do século XX, o grande tema político foi a reivindicação do direito ao voto feminino. Berta Lutz, a grande líder sufragista brasileira, aglutinou um grupo de mulheres da burguesia para divulgar a demanda. Ousadas, espalharam de avião panfletos sobre o Rio de Janeiro, pedindo o voto feminino, no início dos anos 20! Pressionaram

\footnotetext{
${ }_{18}$ Para outros, esta manifestação contra a fome, o czarismo e a guerra teria sido orientada pelo comitê bolchevista de Petrogrado.

${ }^{19}$ Devo 0 acesso ao texto de Clara Zetkin à sempre companheira Judith Patarra.

${ }^{20}$ ZETKIN, 1934 p. 97.

${ }^{21}$ ZETKIN, 1934 p.99.
} 
deputados federais e senadores e se dirigiram ao presidente Getúlio Vargas. Afinal, o direito ao voto feminino foi concedido em 1933 por ele e garantido na Constituição de $1934 .^{22}$ Mas só veio a ser posto em prática com a queda da ditadura getulista, e as mulheres brasileiras votaram pela primeira vez em 1945.

Em 1901, as operárias, que juntamente com as crianças constituíam $72,74 \%$ da mão-de-obra do setor têxtil, denunciavam que ganhavam muito menos do que os homens e faziam a mesma tarefa, trabalhavam de 12 a 14 horas na fábrica e muitas ainda trabalhavam como costureiras, em casa. Como mostra Rago, a jornada era de umas 18 horas e as operárias eram consideradas incapazes física e intelectualmente. Por medo de serem despedidas, submetiam-se também à exploração sexual.

Os jornais operários, especialmente os anarquistas, reproduziam suas reclamações contra a falta de higiene nas fábricas, o assédio sexual, as péssimas condições de trabalho, a falta de pagamento de horas extras, um sem número de abusos. Para os militantes operários, a fábrica era um local onde as mulheres facilmente se prostituíam, daí reivindicarem a volta das mulheres para casa. Patrões, chefes e empregados partilhavam dos mesmos valores: olhavam as trabalhadoras como prostitutas. ${ }^{23}$

Entre as militantes das classes mais altas, a desqualificação do operariado feminino não era muito diferente: partilhavam a imagem generalizada de que operárias eram mulheres ignorantes e incapazes de produzir alguma forma de manifestação cultural. A distância entre as duas camadas sociais impedia que as militantes burguesas conhecessem a produção cultural de anarquistas como Isabel Cerruti e Matilde Magrassi, ou o desempenho de Maria Valverde em teatros populares como o de Arthur Azevedo ${ }^{24}$.

Como as anarquistas americanas e européias, as brasileiras (imigrantes ou não) defendiam a luta de classes mas também o divórcio e o amor livre, como escrevia $A$ Voz do Trabalhador de $1^{\circ}$ de fevereiro de 1915: "Num mundo em que mulheres e homens desfrutassem de condições de igualdade... Vivem juntos porque se querem, se estimam no mais puro, belo e desinteressado sentimento de amor". ${ }^{25}$

A distinção entre anarquistas e comunistas foi fatal para uma eventual aliança: enquanto as comunistas lutavam pela implantação da "ditadura do proletariado", as anarquistas acreditavam que o sistema partidário reproduziria as relações de poder, social e sexualmente hierarquizadas.

No PC a diferenciação de gênero continuava marcante: as mulheres se encarregavam das tarefas 'femininas' na vida quotidiana do Partido. Extremamente ativas, desenvolveram ações externas de organização sem ocupar qualquer cargo importante na hierarquia partidária. Atuavam, por exemplo, junto a crianças das favelas ou dos cortiços, organizavam colônias de férias, supondo que poderiam ensinar às crianças novos valores.

Zuleika Alembert, a primeira mulher a fazer parte da alta hierarquia do PC, eleita deputada estadual por São Paulo em 1945, foi expulsa do Partido quando fez críticas feministas denunciando a sujeição da mulher em seu próprio partido.

O feminismo dos anos 60 e 70 veio abalar a hierarquia de gênero dentro da esquerda. A luta das mulheres contra a ditadura de 1964 uniu, provisoriamente, as feministas e as que se autodenominavam membros do 'movimento de mulheres'. A uni-las, contra os militares, havia uma data: o 8 de Março. A comemoração ocorria através da luta pelo retorno da democracia, de denúncias sobre prisões arbitrárias, desaparecimentos políticos.

${ }^{22}$ ALVES, 1980.

${ }^{23}$ RAGO, 1987.

${ }^{24}$ Agradeço a Miriam Moreira Leite a contribuição para a inclusão destes dados e pela revisão do texto.

${ }^{25}$ RAGO, 1987, p. 104.

ANO $9606 \quad 2 \circ$ SEMESTRE 2001 
A consagração do direito de manifestação pública veio com o apoio internacional - a ONU instituiu, em 1975, o 8 de Março como o Dia Internacional da Mulher.

Entrou-se numa nova etapa do feminismo. Mas velhos preconceitos permaneceram nas entrelinhas. Um deles talvez seja a confusa história propalada do 8 de Março, em que um anti-americanismo apagava a luta de tantas mulheres, obscurecendo até mesmo suas origens étnicas.

\section{Referências bibliográficas}

ALVES, Branca Moreira. Ideologia e feminismo: a luta pelo voto feminino no Brasil. Petrópolis: Vozes, 1980.

BOSI, Ecléa. Simone Weil: a razão dos vencidos. São Paulo: Brasiliense, 1982.

CHEVALIER, Charles. Classes laborieuses et classes dangereuses à Paris pendant la première moitié du XIXe. siècle. Paris: Hachette, 1984.

CHOMBART DE LAUWE, M.J; CHOMBART DE LAUWE, Paul Henri et al. La femme dans la sociétè: son image dans différents milieux sociaux. Paris: CNRS, 1963.

HOWE, Irving; LIBO, Kenneth. How We Lived. A Documentay History of Immigrant Jews in America. 1880-1930. USA: Richard Marek Publishers, 1979.

Isis Creation for the Australian Women's Inta Network. A History of International Women's Day Origins. Disponível em: <http://www.isis.aust.com/iwd>.

LOBO, Elisabeth Souza . Emma Goldman: a vida como revolução. São Paulo: Brasiliense, 1983.

MARIN, Alexandra Ayala. "Caja de Pandora". Clara Zetkin. Entrevista dada para UNIFEM. Disponível em: <www4.ecua.net.ec/unifem/verscon3/entrevsta.htm>.

MINCZELES, Henri. Histoire générale du BUND, un mouvement révolutionnaire juif. Paris: Austral, 1995.

SANDERS, Ronald. The Dowtown Jews. Portraits of an Immigrant Generation. New York: Dover Publications, Inc., 1987.

SHEPHERD, Naomi. A Price Below Rubies. Jewish Women as Rebels and Radicals. Cambridge, Massachusetts: Harvard University Press, 1993.

ZETKIN, Clara. My Recollections of Lenin (An Interview on Woman Question). Apêndice p. 87122. In: V.I. LENIN. The Emancipation of Women . New York: International Publishers, 1972 [1934].

RAGO, Margareth. Do cabaré ao lar: a utopia da cidade disciplinar. 1890-1930. Rio de Janeiro: Paz e Terra, 1987.

The $8^{\text {th }}$ of March: Gains and Controversies

Abstract: Clara Zetkin suggested the creation of the International Women's Day

during the 2nd Socialist Women's International Conference in 1910. After 1970 this date became increasingly associated with a fire that took place in New York City in 1911. In this paper I review the history of the 8th of March, pointing out some of the distortions of its meanings and the repercussions these distortions have had for an understanding of feminist struggles.

Keywords: feminist history, Jewish and Italian female factory workers, politics, social movements. 